\title{
Chryseobacterium paridis sp. nov., an endophytic bacterial species isolated from the root of Paris polyphylla Smith var. yunnanensis
}

\section{Zhen Zhang}

Yunnan University

Ling-Ling Yang

Yunnan University

Cong-Jian Li

Yunnan University

\section{Xing-Wang Jiang}

Yunnan University

Xiao-Yang Zhi ( $\nabla$ xyzhi@ynu.edu.cn )

Yunnan University https://orcid.org/0000-0002-9862-377X

\section{Research Article}

Keywords: Chryseobacterium paridis sp. nov., Novel species, polyphasic taxonomy, the root of Paris polyphylla Smith var. yunnanensis

Posted Date: May 24th, 2021

DOI: https://doi.org/10.21203/rs.3.rs-526912/v1

License: (c) (i) This work is licensed under a Creative Commons Attribution 4.0 International License. Read Full License

Version of Record: A version of this preprint was published at Archives of Microbiology on August 3rd, 2021. See the published version at https://doi.org/10.1007/s00203-021-02504-2. 
1 Chryseobacterium paridis sp. nov., an endophytic bacterial species isolated from the

root of Paris polyphylla Smith var. yunnanensis

\author{
Zhen Zhang ${ }^{\dagger}$, Ling-Ling Yang ${ }^{\dagger}$, Cong-Jian Li, Xing-Wang Jiang, Xiao-Yang Zhi*
}

Yunnan Institute of Microbiology, School of Life Sciences, Yunnan University, Kunming 650091, People's Republic of China

$\nmid$ These authors contributed equally to this work.

* Correspondence: Xiao-Yang Zhi, Email: xyzhi@ynu.edu.cn

Abbreviations: GCM, the Global Catalogue of Microorganisms; MK, menaquinone; NJ,

neighbor-joining; MP, maximum-parsimony; ML, maximum-likelihood; AAI, average amino acid identity; ANI, average nucleotide identity; dDDH, digital DNA-DNA hybridization; PE, phosphatidylethanolamine; AL, unidentified aminolipid; GL, unidentified glycolipid; L, unidentified lipid. 
Abstract

A Gram-negative, yellow-pigmented, rod-shaped bacterial strain YIM B $02567^{\mathrm{T}}$ was isolated from the root of Paris polyphylla Smith var. yunnanensis in China. Strain YIM B02567 ${ }^{\mathrm{T}}$ grew optimally at $25-30^{\circ} \mathrm{C}$ and at $\mathrm{pH} 7.0$ in the absence of $\mathrm{NaCl}$ on nutrient agar. Phylogenetic analyses based on $16 \mathrm{~S}$ rRNA gene sequences revealed that strain YIM B $02567^{\mathrm{T}}$ belong to the genus Chryseobacterium, and closely related to Chryseobacterium piperi $\mathrm{CTM}^{\mathrm{T}}$ and Chryseobacterium soli DSM $19298^{\mathrm{T}}$. Whole genome sequencing indicated that the genome size was 4,774,612 bp and had a DNA G+C content of $34.5 \%$. Values of the ANI and the dDDH between strain YIM B02567 $7^{\mathrm{T}}$ and its closely related Chryseobacterium species were below $81.72 \%$ and $24.7 \%$. Strain YIM B $02567^{\mathrm{T}}$ contained menaquinone- 6 as the sole isoprenoid quinone, anteiso- $\mathrm{C}_{15: 0}$, iso- $\mathrm{C}_{17: 1} \omega 9 c$ and iso- $\mathrm{C}_{17: 0} 3-\mathrm{OH}$ as major fatty acids and phosphatidylethanolamine as major polar lipid. Based on the polyphasic analyses, strain YIM B $02567^{\mathrm{T}}$ could be differentiated genotypically and phenotypically from recognized species of the genus Chryseobacterium. The isolate therefore represents a novel species, for which the name Chryseobacterium paridis sp. nov. is proposed. The type strain is YIM B02567 $\left(=\right.$ CGMCC $\left.1.18657^{\mathrm{T}}\right)$.

Keywords: Chryseobacterium paridis sp. nov.; Novel species; polyphasic taxonomy; the root of Paris polyphylla Smith var. yunnanensis 


\section{Introduction}

The Genus Chryseobacterium, proposed by Vandamme et al. (1994) and was emended from the genus Flavobacterium, based on the genotypic, biochemical and phenotypic characteristics of the organisms (Bernardet et al. 1996). At the time of writing, more than one hundred valid published species of the genus Chryseobacterium have been reported (https://lpsn.dsmz.de/genus/chryseobacterium); many of these are abundant in diverse environments, including soil (Benmalek et al. 2010), water (Montero-Calasanz et al. 2013), plants (Du et al. 2015), rhizospheres (Park et al. 2006), raw milk (Hantsis-Zacharov et al 2007), chicken (Kämpfer et al. 2014) and fish (Ilardi et al. 2009). Interestingly, several species of the genus Chryseobacterium, isolated from plants or rhizospheres. In this genus, it has many rhizospheric microorganisms, for example, Chryseobacterium cucumeris isolated from cucumber (Cucumis sativus L.) root (Jeong et al. 2017). Chryseobacterium ginsengisoli isolated from the rhizosphere of ginseng (Nguyen et al. 2013), Chryseobacterium ginsenosidimutans isolated from soil of a Rhus vernicifera-cultivated field (Im et al. 2011). In this study, we described a new species of the genus Chryseobacterium, designated YIM B $02567^{\mathrm{T}}$, isolated from the root of Paris polyphylla var. yunnanensis.

\section{Materials and methods}

\section{Bacterial isolation and maintenance}

Healthy root samples of $P$. polyphylla var. yunnanensis were collected from Shilin in Yunnan province, south-west PR China. Samples were sterilized and pulverized before distribution on nutrient agar (NA) medium as described by Yang et al. (2016). After incubation at $28{ }^{\circ} \mathrm{C}$ for 2 weeks, different clonies were randomly selected and their $16 \mathrm{~S}$ rRNA genes were PCR-amplified. Strain YIM B02567 ${ }^{\mathrm{T}}$ was selected as a putative novel species of the genus Chryseobacterium for further taxonomic characterizations. The purified strain was preserved both on NA slants at $4{ }^{\circ} \mathrm{C}$ and in $20 \%$ (v/v) glycerol at $-80{ }^{\circ} \mathrm{C}$ for further use.

\section{S rRNA gene sequencing and phylogenetic analysis}

Genomic DNA of strain YIM B $02567^{\mathrm{T}}$ was extracted using a genomic DNA extraction kit (Tiangen, China). The $16 \mathrm{~S}$ rRNA gene was amplified by PCR using forward primer 27F (5'-AGA GTT TGA 
TCC TGG CT-3') and reverse primer 1492R (5'-GGT TAC CTT GTT ACG ACT T-3'). Amplified products were purified and cloned into vector pClone007 (TsingKe, China). The 16S rRNA gene sequence (1536 bp) of strain YIM B $02567^{\mathrm{T}}$ was checked manually and submitted to the GenBank database. The similarities of $16 \mathrm{~S}$ rRNA gene sequences between strain YIM B $02567^{\mathrm{T}}$ and closely related type strains were calculated using the EZBioCloud server (https://www.ezbiocloud.net/) (Yoon et al. 2017). The 16S rRNA gene sequences were aligned by using Clustal Omega (Sievers et al. 2011) software and Kimura's two-parameter model (Kimura 1980). Phylogenetic trees were constructed with the Neighbour-joining (NJ) (Saitou and Nei 1987), Maximum-likelihood (ML) (Felsenstein 1981) methods using Mega X software (Kumar et al. 2018). Bootstrap analysis with 1000 replicates was conducted to assess confidence levels for the branches (Felsenstein 1985).

\section{Whole genome sequencing and analysis}

The whole-genome sequencing of strain YIM B $02567^{\mathrm{T}}$ was performed using BGISEQ platform by China General Microbiological Culture Collection Center (CGMCC) as part of the Global Catalogue of Microorganisms (GCM) 10K project (Shi et al. 2021). The sequence data were assembled using SOAPdenovo 2.04 ( $\mathrm{Li}$ et al. 2015). The average nucleotide identity (ANI) values between strains YIM $\mathrm{B} 02567^{\mathrm{T}}$ and reference strains were calculated using FastANI (Jain et al. 2018). Average amino acid identity (AAI) values were calculated from protein sequences by using an online AAI calculator (http://enve-omics.ce.gatech.edu/aai/). The estimated genome-sequence based digital DNA-DNA hybridization $(\mathrm{dDDH})$ values were calculated using formula 2 at the Genome-to-Genome Calculator (CGGC) website (https://ggdc.dsmz.de/ggdc.php) as described by Meier-Kolthof et al. (2013).

For further confirming the taxonomy status, phylogenomic analysis of strain YIM B $02567^{\mathrm{T}}$ and related species was performed. Genome sequences of the related species' type strains were collected from NCBI GenBank Database. And all of these genomes were annotated by using PROKKA (Seemann 2014). The orthologous gene inferring was using by OrthoFinder (Emms et al. 2015). The selected orthologs were aligned by using the Clustal Omega (Sievers et al. 2011) and concatenating all alignments. Gblocks (Castresana 2000) was used to select the conserved blocks from the concatenation. The reconstruction of a ML tree was using IQ-tree (Nguyen et al. 2015).

\section{Morphology and physiology and biochemical analysis}


Cell morphology was observed by scanning electron microscope after growth for 2 days in Reasoner's $2 \mathrm{~A}(\mathrm{R} 2 \mathrm{~A})$ medium at $30^{\circ} \mathrm{C}$. The Gram reaction was performed using $3 \%(\mathrm{w} / \mathrm{v}) \mathrm{KOH}$ for cell lysis. The growth of the strain was assessed by incubating inoculated R2A plates in a bacteria culture box at $30{ }^{\circ} \mathrm{C}$ for 7 days. Growth was examined at different temperatures (low to $20^{\circ} \mathrm{C}$, up to $50{ }^{\circ} \mathrm{C}$, at intervals of $5{ }^{\circ} \mathrm{C}$ ) and $\mathrm{NaCl}$ concentrations (up to $5.0 \%$, at intervals of $0.5 \%$, w/v) for 7 days. The $\mathrm{pH}$ range for growth was tested between 4.0 and 10.0, at intervals of $1.0 \mathrm{pH}$ unit in R2A broths prepared by using the buffer system described by Nie et al. (2012). Catalase activity was determined from the production of gas bubbles on the addition of a drop of $3 \%(\mathrm{v} / \mathrm{v}) \mathrm{H}_{2} \mathrm{O}_{2}$. Oxidase activity was detected using API oxidase reagent (bioMérieux) according to the manufacturer's instructions. Carbon source utilization was checked in Biolog GENIII microplates. Additional biochemical characteristics and enzymatic activities were further determined using the API 20NE and API ZYM kits (bioMérieux) according to the instructions provided by the manufacturers.

\section{Chemotaxonomic characterization}

The fatty acid profile, polar lipids and respiratory quinones of strain YIM B $02567^{\mathrm{T}}$ were analyzed in this study. To assess the fatty acids, strain YIM B $02567^{\mathrm{T}}$ were cultured on R2A agar plates at $30^{\circ} \mathrm{C}$ for 2 days. After saponification and methylation, fatty acids were extracted using a standard protocol and the Sherlock Microbial Identification (Sherlock version 6.1; MIDI database: TSBA6) according to the manufacturer's instructions (Sasser 2001) and analysed on Agilent 7890A gas chromatography apparatus. Respiratory quinones and polar lipids were extracted from freeze-dried cells using the method described by Collins et al. (1977). Subsequently, quinones were analysed by a reversed-phase HPLC system (Agilent Technologies 1260 Infinity) with a C18 column $(25 \mathrm{~cm} \times 4.6 \mathrm{~mm}, 5 \mu \mathrm{m})$. Extracted total lipids from strain YIM B02567 ${ }^{\mathrm{T}}$ were examined by a two-dimensional TLC procedure on silica gel G60 plates (Hasegawa et al 1983; Minnikin et al. 1984). For the presence of all lipids, TLC plates were sprayed with $5 \%$ molybdophosphoric acid. Besides, $0.2 \%$ ninhydrin was used to detect aminolipids, molybdenum blue spray reagent was used to detect phospholipids and $a$-naphthol reagent was used to detect glycolipids.

\section{Results and discussion}

\section{Phylogenetic and whole-genome analysis}


The cloned sequence of the 16S rRNA gene of YIM B02567 ${ }^{\mathrm{T}}$ has been deposited in NCBI GenBank under accession number (MW911623). Analysis of its 16S rRNA gene sequence revealed that strain YIM B $02567^{\mathrm{T}}$ belonged to the genus Chryseobacterium and had highest gene sequence similarities to

C. soli DSM $19298^{\mathrm{T}}$ (97.8 \%), Chryseobacterium ginsenosidimutans THG $15^{\mathrm{T}}(97.7 \%)$, Chryseobacterium soldanellicola DSM $17072^{\mathrm{T}}(97.5 \%)$ and C. piperi $\mathrm{CTM}^{\mathrm{T}}(97.4 \%)$. The NJ phylogenetic tree based on 16S rRNA gene sequences showed that strain YIM B02567 ${ }^{\mathrm{T}}, C$. soli and $C$. piperi formed a monophyletic clade (Fig 1), but did not clustered with C. ginsenosidimutans and $C$. soldanellicola. This topology relationship was supported by the ML tree. (Fig S3). Furthermore, a ML phylogenomic tree reconstructed using 1113 orthologous genes confirm that strain YIM B02567 ${ }^{\mathrm{T}}$ is most closely with C. piperi $\mathrm{CTM}^{\mathrm{T}}$ (Fig 2). strains Genome Database. The GenBank and the GCM accession numbers are JAENHK000000000 and GCM60020044 respectively. The draft genome of strain YIM B02567 ${ }^{\mathrm{T}}$ contained 12 scaffolds, with a total length of 4,774,612 bp and the N50 length of 2,588,358 bp. The DNA G+C content of strain YIM B $02567^{\mathrm{T}}$ was determined from the genome to be $34.5 \%$. The annotated result of YIM B02567 genome contains 4236 genes, included 4153 protein-coding genes, 3 rRNA genes, 63 tRNA genes and 3 other RNA genes. The ANI values between strain YIM B02567 ${ }^{\mathrm{T}}$ and its closely related strains $C$. piperi $\mathrm{CTM}^{\mathrm{T}}$ and C. soli DSM $19298^{\mathrm{T}}$ were $81.72 \%$ and $78.94 \%$, respectively. ANI values between YIM B02567 ${ }^{\mathrm{T}}$ and other species of Chryseobacterium are shown in Table S1. Strain YIM B02567 $7^{\mathrm{T}}$ has AAI values ranging from $78.77 \%-86.67 \%$ with the all reference genomes (Table S1). The ANI and AAI values were significantly lower than the widely accepted threshold for describing prokaryote species (95-96\%; Kim et al. 2014, Konstantinidis and Tiedje 2005). The dDDH values of strain YIM B02567 ${ }^{\mathrm{T}}$ to C. piperi $\mathrm{CTM}^{\mathrm{T}}$ and C. soli DSM $19298^{\mathrm{T}}$ were $24.7 \%$ and $22.2 \%$, which were significantly lower than $70 \%$ similarity of the species defined threshold (Chun et al. 2018). Therefore, according to the results of OGRIs (overall genome relatedness indices), strain YIM B02567 $7^{\mathrm{T}}$ can represent a novel species of the genus Chryseobacterium.

\section{Morphology, physiology and biochemical analysis}

Cells of strain YIM B02567 $7^{\mathrm{T}}$ were Gram-reaction-negative, aerobic, rod-shaped (Fig. S1). Colonies on R2A agar were deep orange and smooth after incubation at $30^{\circ} \mathrm{C}$ for 2 days. Strains were able to grow 
at temperatures ranging between 10 and $45^{\circ} \mathrm{C}$ (optimum, $30^{\circ} \mathrm{C}$ ), $\mathrm{pH} 5.0-8.0$ (optimum, $\mathrm{pH} 7.0$ ) and in the presence of up to $2.0 \%(\mathrm{w} / \mathrm{v}) \mathrm{NaCl}$ with optimum growth at non-additional $\mathrm{NaCl}$ on $\mathrm{R} 2 \mathrm{~A}$.YIM B $02567^{\mathrm{T}}$ were catalase and oxidase positive. In the API ZYM tests, strain YIM B02567 ${ }^{\mathrm{T}}$ was positive for alkaline phosphatase, esterase (C4), esterase lipase (C8), leucine arylamidase, valine arylamidase, acid phosphatase, and weakly positive for cystine arylamidase activities. The substrate utilization of the strain contained dextrin, D-maltose, D-trehalose, D-fructose, L-fucose, D-mannitol, Glycerol, D-glucose-6-phosphate, D-fructose-6-phosphate, Tween 40, D-glucose-6-phosphate, D-fructose-6-phosphate, gelatin, glycyl-L-prolin, L-alanine, L-arginine, L-aspartic acid, L-glutamic acid, L-serine, glucuronamide, $\alpha$-keto-glutaric acid, acetoacetic acid and propionic acid. Detail characteristics of the novel strain were summarized in the species description and compared to those of closely related strains in Table 1.

\section{Chemotaxonomic characterization}

The major cellular fatty acids of strain YIM B02567 ${ }^{\mathrm{T}}$ were iso- $\mathrm{C}_{15: 0}(41.8 \%)$, iso- $\mathrm{C}_{17: 0} 3-\mathrm{OH}(16.9 \%)$, iso- $\mathrm{C}_{17: 1} \omega 9 c(14.0 \%)$, Summed Feature $3\left(\mathrm{C}_{16: 1} \omega 5 c\right.$ and/or $\left.\mathrm{C}_{16: 1} \omega 6 c, 13.9 \%\right)$. Strain YIM B02567 showed a similar major fatty acid composition to the related type strains of Chryseobacterium species. However, some qualitative and quantitative differences in the fatty acid compositions were observed between the novel strain and the other closely related Chryseobacterium species (Table 2). The major polar lipids of strain YIM B02567 ${ }^{\mathrm{T}}$ was phosphatidylethanolamine (PE).Three unidentified aminolipids (AL), five unidentified glycolipids (GL) and three unidentified lipids (L) were also detected (Fig. S2). The predominant sole respiratory ubiquinone was found to be MK-6, which is the typical ubiquinone of the genus Chryseobacterium.

\section{Taxonomic conclusion}

Based on morphological, physiological, and chemotaxonomic properties, and phylogenetic analysis, strain YIM B $02567^{\mathrm{T}}$ could be considered a representative of a novel species belonging in the genus Chryseobacterium, for which the name Chryseobacterium paridis sp. nov. is proposed.

\section{Description of Chryseobacterium paridis sp. nov.} strain was isolated). 

after 2 days of incubation at $30^{\circ} \mathrm{C}$. Growth occurs at $10-45^{\circ} \mathrm{C}$ (optimum, $30^{\circ} \mathrm{C}$ ), at $\mathrm{pH} 5.0-8.0$ (optimum, $\mathrm{pH} 7.0$ ) and in the presence of $0-2 \% \mathrm{NaCl}$ (optimum, $0 \%$ ). Catalase and oxidase activities are positive. Positive for hydrolysis of esculin and gelatin, but negative for reduction of nitrate to nitrite, indole production, fermentation of glucose, arginine dihydrolase, hydrolysis of urea and 4-nitrophenyl- $\beta$ D-galactopyranoside. In Biolog GENIII microplates, positive for utilization of dextrin, D-maltose, D-trehalose, L-fucose, D-fructose, D-mannitol, glycerol, Tween 40, D-glucose-6-phosphate, D-fructose-6-phosphate, gelatin, glycyl-L-prolin, L-alanine, L-arginine, L-aspartic acid, L-glutamic acid, L-serine, glucuronamide, $\alpha$-keto-glutaric acid, acetoacetic acid and propionic acid; negative for the remaining utilization tests. In the API ZYM system, positive for alkaline phosphatase, esterase (C4), esterase lipase (C8), leucine arylamidase, valine arylamidase, acid phosphatase; weakly positive for cystine arylamidase; but negative for lipase (C14), trypsin, $\alpha$-chymotrypsin, naphthol-AS-BI-phosphohydrolase, $\alpha$-galactosidase, $\beta$-galactosidase, $\beta$-glucuronidase, $\alpha$-glucosidase,

$190 \beta$-glucosidase, $N$-acetyl- $\beta$-glucosaminidase, $\alpha$-mannosidase and $\alpha$-fucosidase. Only MK- 6 is detected as 191 the isoprenoid quinone. Major cellular fatty acids are anteiso- $\mathrm{C}_{15: 0}$, iso- $\mathrm{C}_{17: 1} \omega 9 \mathrm{c}$ and iso- $\mathrm{C}_{17: 0} 3-\mathrm{OH}$. Phosphatidylethanolamine is detected as major polar lipid.

The type strain is YIM B $02567^{\mathrm{T}}$, isolated from a root of P. polyphylla var. yunnanensis collected from Shilin, Yunnan Province, southwest PR China. The DNA G+C content of the type strain is $34.5 \%$ (genome). The GenBank accession number for the 16S rRNA gene of strain YIM B02567 ${ }^{\mathrm{T}}$ is MW911623. The whole genome sequences have been deposited at GenBank and GCM under accession JAENHK000000000 and GCM60020044, respectively.

\section{Declarations}

Funding This research was supported by the National Natural Science Foundation of China (grant number: 32060003); 
Code availability Not applicable

Authors' contributions Zhen Zhang, Cong-Jian Li and Xing-Wang Jiang performed the experiments; Zhen Zhang and manuscript.

\section{Compliance with ethical standards}

Ethical approval This article does not contain any studies with human participants or animals performed by any of the authors.

Consent for publication The manuscript is submitted with the consent of all authors.

\section{References}

Benmalek Y, Cayol J-L, Bouanane NA, Hacene H, Fauque G, Fardeau M-L (2010) Chryseobacterium solincola sp nov., isolated from soil. Int J Syst Evol Microbiol 60(8):1876-1880. https://doi.org/10.1099/ijs.0.008631-0

Castresana J (2000) Selection of conserved blocks from multiple alignments for their use in phylogenetic analysis. Mol

Chun J, Oren A, Ventosa A, Christensen H, Arahal DR, da Costa MS, Rooney AP, Yi H, Xu X-W, Meyer SD, Trujillo ME (2018) Proposed minimal standards for the use of genome data for the taxonomy of prokaryotes. Int J Syst Evol corynebacteria. J Gen Microbiol 100(2):221-230. https://doi.org/10.1099/00221287-100-2-221 

improves orthogroup inference accuracy. Genome Biol 16(1):157. https://doi.org/10.1186/s13059-015-0721-2.

234 Felsenstein J (1981) Evolutionary trees from DNA sequences: a maximum likelihood approach. J Mol Evol 17:368-376. https://doi.org/10.1007/BF017 34359

Felsenstein J (1985) Confidence limits on phylogenies: an approach using the bootstrap. Evolution 39:783-791. https://doi.org/10.1111/j.1558-5646.1985.tb004 20.x

Hantsis-Zacharov E, Halpern M (2007) Chryseobacterium haifense sp nov., a psychrotolerant bacterium isolated from raw milk. Int J Syst Evol Microbiol 57(10):2344-2348. https://doi.org/10.1099/ijs.0.65115-0

Ilardi P, Fernández J, Avendaño-Herrera R (2009) Chryseobacterium piscicola sp nov., isolated from diseased salmonid fish. J Syst Evol Microbiol 59(12):3001-3005. https://doi.org/10.1099/ijs.0.007021-0

Jain C, Rodriguez-R LM, Phillippy AM, Konstantinidis KT, Aluru S (2018) High throughput ANI analysis of 90K nucleotide sequences. J Mol Evol 16:111-120. https://doi.org/10.1007/BF017 31581 

Computing Platforms. Mol Biol Evol 35:1547-1549. https ://doi.org/10.1093/molbev/msy096

Li D, Liu CM, Luo R, Sadakane K, Lam TW (2015) MEGAHIT: an ultra-fast single-node solution for large and complex metagenomics assembly via succinct de Bruijn graph. Bioinformatics 31:1674-1676. https ://doi.org/10.1093/bioin forma tics/btv033

Meier-Kolthof JP, Auch AF, Klenk H-P, Göker M (2013) Genome sequence-based species delimitation with confdence intervals and improved distance functions. BMC Bioinformatics 14:60. https://doi.org/10.1186/1471-2105-14-60

Montero-Calasanz MDC, Göker M, Rohde M, Spröer C, Schumann P, Busse H-J, Schmid M, Tindall BJ, Klenk H-P,

Saitou N, Nei M (1987) The neighbor-joining method: a new method for reconstructing phylogenetic trees. Mol Biol 

https://doi.org/10.1093/bioinformatics/btu153

293 Shi W, Sun Q, Fan G, Hideaki S, Moriya O, Itoh T et al. (2021) gcType: a high-quality type strain genome database for microbial phylogenetic and functional research. Nucleic Acids Res 49(D1):D694-D705. https://doi.org/10.1093/nar/gkaa957

Sievers F, Wilm A, Dineen D, Gibson TJ, Karplus K et al. (2011) Fast, scalable generation of high-quality protein multiple sequence alignments using Clustal Omega. Mol Syst Biol 7:539. https://doi.org/10.1038/msb.2011.75

Singh P, Kim Y-J, Farh ME-A, Dan WD, Kang CH, Yang D-C (2016) Chryseobacterium panacis sp. nov., isolated from ginseng soil. Antonie van Leeuwenhoek 109(2), 187-196. https://doi.org/10.1007/s10482-015-0620-2 nov., isolated from a freshwater creek. Int J Syst Evol Microbiol 61(9):2162-2166. https://doi.org/10.1099/ijs.0.027805-0 Flavobacteria: description of Chryseobacterium gen. nov., Bergeyella gen. nov., and Empedobacter nom. rev. Int J Syst Bacteriol 44:827-831. https://doi.org/10.1099/00207713-44-4-827

Yang L-L, Tang S-K, Chu X, Jiang Z, Xu L-H, Zhi X-Y (2016) Oceanobacillus endoradicis sp. nov., an endophytic bacterial species isolated from the root of Paris polyphylla Smith var. yunnanensis. Antonie Van Leeuwenhoek 109(7):957-64. https://doi.org/10.1007/s10482-016-0695-4

Yoon S-H, Ha S-M, Kwon S, Lim J, Kim Y, Seo H, Chun J (2017) Introducing EzBioCloud: a taxonomically united database of 16S rRNA gene sequences and whole-genome assemblies. Int J Syst Evol Microbiol 67:1613-1617. https://doi.org/10.1099/ijsem .0.001755 
Table 1. Diferential characteristics of YIM B $02567^{\mathrm{T}}$ and related species of the genus

Chryseobacterium.

\begin{tabular}{|c|c|c|c|c|c|}
\hline Characteristics & 1 & 2 & 3 & 4 & 5 \\
\hline Optimum temperature $\left({ }^{\circ} \mathrm{C}\right)$ & $28-30$ & $20-30$ & $28-30$ & $25-30$ & $25-30$ \\
\hline Range of temperature $\left({ }^{\circ} \mathrm{C}\right)$ & $10-40$ & $5-37$ & $5-30$ & $5-42$ & $10-37$ \\
\hline Optimum pH & 7.0 & $6.5-8.0$ & $6.0-7.0$ & 5.0 & 7.0 \\
\hline Range of $\mathrm{pH}$ & $6.0-9.0$ & $6.0-10.0$ & $5.0-9.0$ & $5.0-7.0$ & $5.5-10.0$ \\
\hline $\mathrm{NaCl}$ tolerance $(\%)$ & 2 & 2 & 3 & 4 & 1 \\
\hline Indole production & - & + & - & - & - \\
\hline Arginine dihydrolase & - & - & - & - & + \\
\hline Hydrolysis of urea & - & + & + & - & + \\
\hline 4-Nitrophenyl $\beta \mathrm{D}$-galactopyranoside & - & + & - & - & - \\
\hline \multicolumn{6}{|l|}{ Enzyme activity of: } \\
\hline Esterase (C4) & + & $\mathrm{W}$ & + & + & - \\
\hline Cystine arylamidase & w & w & + & - & - \\
\hline Trypsin & - & - & + & - & - \\
\hline Naphthol-AS-BI-phosphohydrolase & - & + & + & + & + \\
\hline$\alpha$-Glucosidase & - & + & + & + & + \\
\hline$\beta$-Glucosidase & - & - & - & - & + \\
\hline$N$-acetyl- $\beta$-Glucosaminidase & - & + & + & - & + \\
\hline \multicolumn{6}{|l|}{ Utilization of: } \\
\hline D-Glucose & - & w & + & w & + \\
\hline L-Arabinose & - & - & - & $\mathrm{w}$ & + \\
\hline D-Mannose & - & $\mathrm{W}$ & + & $\mathrm{W}$ & + \\
\hline D-Mannitol & + & $\mathrm{w}$ & - & - & - \\
\hline DNA G+C content $(\%)^{*}$ & 34.5 & 35.2 & 36.4 & 35.4 & 35.7 \\
\hline
\end{tabular}

Taxa: 1, YIM B02567 $; 2$, C. piperi $\mathrm{CTM}^{\mathrm{T}}$ (Strahan et al. 2011); 3, C. soli DSM $19298^{\mathrm{T}}$ (Weon et al. 2008); 4, C. soldanellicola PSD1-4 ${ }^{\mathrm{T}}$ (Park et al. 2006); 5, C. ginsenosidimutans THG $15^{\mathrm{T}}$ (Im et al. 2011). *, The DNA G+C contents were calculated based on their genome sequences in this study, except $C$. ginsenosidimutans THG $15^{\mathrm{T}}$. All strains were Gram-negative rods, catalase and oxidase positive. In API $20 \mathrm{NE}$ and API ZYM kits, all strains were positive for the following characteristics: hydrolysis of esculin and gelatin; alkaline phosphatase, esterase lipase (C8), leucine arylamidase, valine arylamidase, acid phosphatase. All strains were negative for the following characteristics: reduction of nitrate to nitrite, fermentation of glucose, lipase (C14), $\alpha$-chymotrypsin, $\alpha$-galactosidase, $\beta$-galactosidase, $\beta$-glucuronidase, $\alpha$-mannosidase and $\alpha$-fucosidase. Symbols: + , positive; - , negative; $\mathrm{w}$, weakly positive. 
Table 2. Cellular fatty acid composition of strains YIM $\mathrm{B} 02567^{\mathrm{T}}$ and the type strains of related Chryseobacterium species.

\begin{tabular}{|c|c|c|c|c|c|}
\hline Fatty Acid & 1 & 2 & 3 & 4 & 5 \\
\hline \multicolumn{6}{|l|}{ Saturated } \\
\hline $\mathrm{C}_{16: 0}$ & 2.0 & 1.1 & 1.6 & 1.4 & - \\
\hline $\mathrm{C}_{16: 0} 3-\mathrm{OH}$ & 1.7 & 1.8 & 1.3 & 1.6 & - \\
\hline \multicolumn{6}{|l|}{ Branched-chain: } \\
\hline iso- $\mathrm{C}_{13: 0}$ & $\operatorname{tr}$ & 1.1 & 1.0 & 1.8 & - \\
\hline iso- $\mathrm{C}_{15: 0}$ & 41.8 & 36.6 & 36.5 & 40.4 & 50.3 \\
\hline anteiso- $\mathrm{C}_{15: 0}$ & $\operatorname{tr}$ & $\operatorname{tr}$ & 2.6 & 2.7 & 3.8 \\
\hline iso- $\mathrm{C}_{17: 1} \omega 9 c$ & 14.0 & 22.0 & 16.9 & 12.2 & 9.3 \\
\hline iso- $\mathrm{C}_{17: 0}$ & $\operatorname{tr}$ & $\operatorname{tr}$ & 1.3 & $\operatorname{tr}$ & - \\
\hline \multicolumn{6}{|l|}{ Hydroxy: } \\
\hline iso- $\mathrm{C}_{15: 0} 3-\mathrm{OH}$ & 3.5 & 4.2 & 2.8 & 3.6 & 5.2 \\
\hline iso- $\mathrm{C}_{16: 0} 3-\mathrm{OH}$ & $\operatorname{tr}$ & 1.8 & 1.3 & 1.6 & - \\
\hline iso- $\mathrm{C}_{17: 0} 3-\mathrm{OH}$ & 16.9 & 17.9 & 20.7 & 19.8 & 21.9 \\
\hline $\mathrm{C}_{17: 0} 2-\mathrm{OH}$ & $\operatorname{tr}$ & $\operatorname{tr}$ & 1.1 & $\operatorname{tr}$ & - \\
\hline Summed Feature 3 & 13.9 & 12.6 & 11.9 & 11.8 & 9.5 \\
\hline
\end{tabular}

326 Taxa: 1, YIM B02567 $;$; , C. piperi $\mathrm{CTM}^{\mathrm{T}} ; 3$, C. soli $\mathrm{JS6}^{\mathrm{T}} 6^{\mathrm{T}} ;$ 4, C. soldanellicola PSD1-4 ${ }^{\mathrm{T}} ; .5, C$.

327 ginsenosidimutans THG $15^{\mathrm{T}}$ (Im et al. 2011). Data for columns 2-4 were taken from Strahan et al. (2011). Summed features represent groups of two or three fatty acids that cannot be separated using MIDI system. Summed feature 3, $\mathrm{C}_{16: 1} \omega 7 c$ and/or $\mathrm{C}_{16: 1} \omega 6 c$. Symbols: tr, trace amount $(<1.0 \%)$; , not detected. 
Fig. 1. A neighbour-joining phylogenetic tree based on 16S rRNA gene sequences showing the phylogenetic relationships between strain YIM B $02567^{\mathrm{T}}$ and members of the genus Chryseobacterium. Bootstrap values (expressed as percentages of 1000 replications) of above 50\% are shown at branch points. Bar, 0.006 substitutions per nucleotide position.

Fig. 2. Maximum-likelihood phylogenomic tree showing the position of strain YIM B02567 ${ }^{\mathrm{T}}$ and related taxa. Bootstrap values of $100 \%$ are shown. The scale bar denotes the number of accepted substitutions per site. 


\section{Figures}

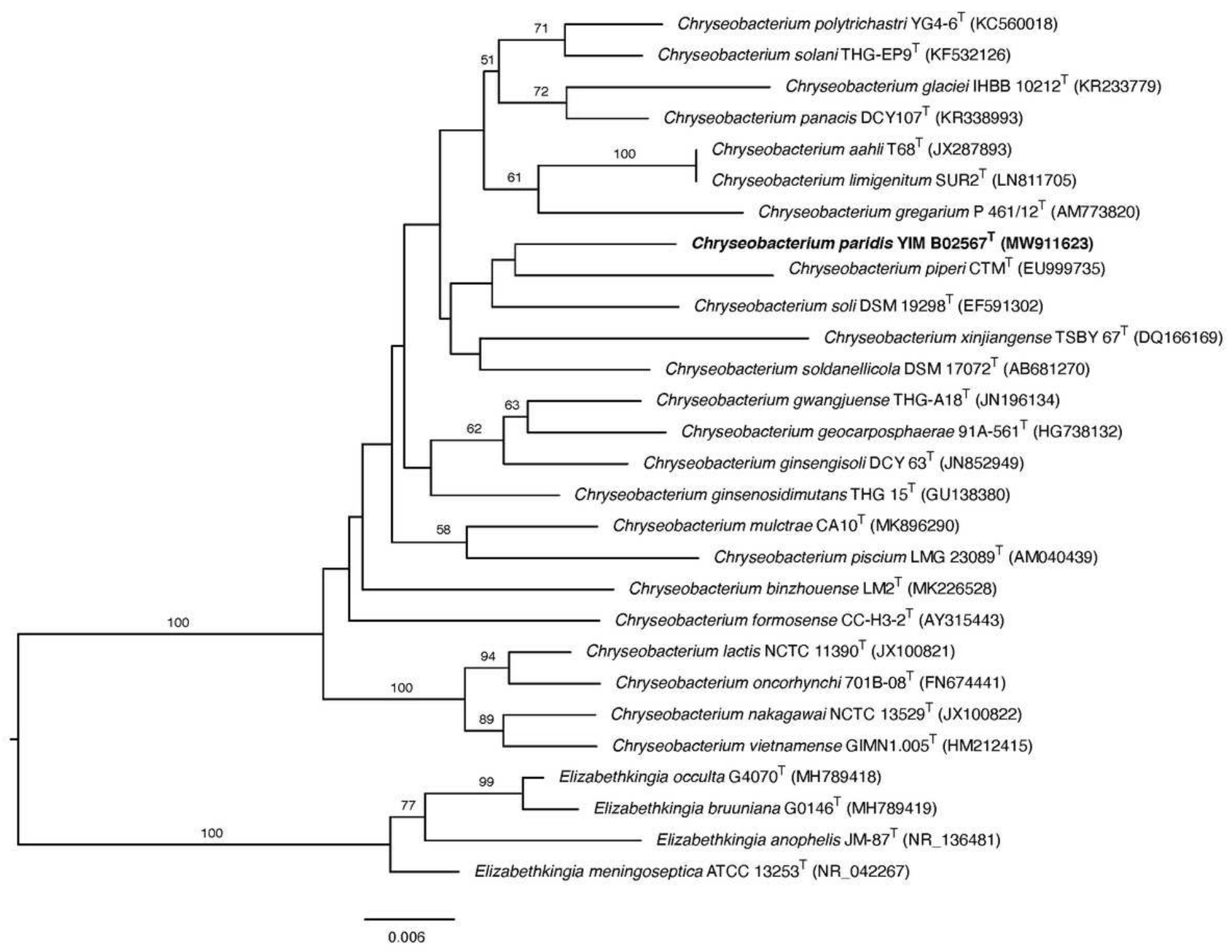

\section{Figure 1}

A neighbour-joining phylogenetic tree based on 16S rRNA gene sequences showing the phylogenetic relationships between strain YIM B02567T and members of the genus Chryseobacterium. Bootstrap values (expressed as percentages of 1000 replications) of above 50\% are shown at branch points. Bar, 0.006 substitutions per nucleotide position. 


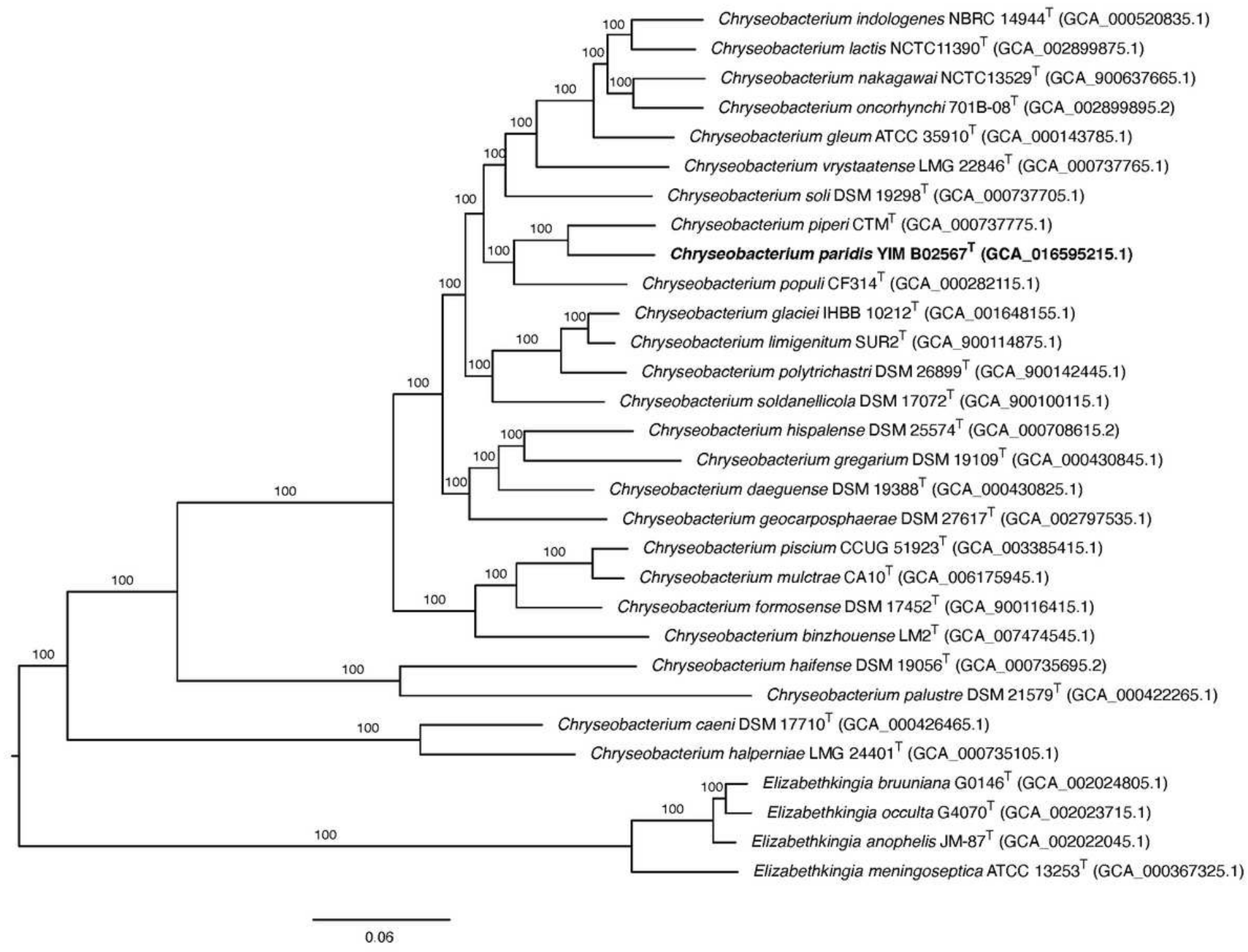

\section{Figure 2}

Maximum-likelihood phylogenomic tree showing the position of strain YIM B02567T and related taxa. Bootstrap values of $100 \%$ are shown. The scale bar denotes the number of accepted substitutions per site.

\section{Supplementary Files}

This is a list of supplementary files associated with this preprint. Click to download.

- Supplementarymaterials3clean.pdf 